\title{
Estimation of infiltration rate based on complementary error function peak for Ozat watershed in Gujarat (India)
}

\begin{abstract}
Infiltration refers to the downward movement of water into the soil from the surface, driven by force of gravity and capillary attraction. Infiltration of water in unsaturated soils has long been an important impact in soil science, hydrology, and geotechnical engineering. Fieldmeasurement of infiltration is very tedious and time consumingand, hence, it is often estimated from different conceptual models. Thus, in the present study, a model based on complementary error function peak (ERFC) is proposed to determine infiltration rate for the Ozat Watershed of Gujarat (India). The two quantitative standard statistical performance evaluation measures, refined Willmott's index $\left(\mathrm{d}_{\mathrm{r}}\right)$ and mean absolute error (MAE) are employed in comparingand evaluating the performance of theproposed model with existing Horton's, Modified Kostiakov, and Green-Ampt infiltration models. The results of the models are validated with the Double-ring infiltrometer field data of different soil types. The proposed ERFC based model was judged to be more consistent with $\mathrm{d}_{\mathrm{r}}=(0.87$ to 0.90$)$ and MAE $=\left(0.47\right.$ to $\left.0.27 \mathrm{~cm} / \mathrm{h}_{\mathrm{r}}\right)$. The results presented in this work are quite encouraging. Further the findings indicate that the use of ERFC based proposed model appears to be the most suitable and appropriate for estimation of infiltration rate in Ozat watershed.
\end{abstract}

Keywords: infiltration, infiltration rate, infiltration models, ERFC, Ozat watershed
Volume 2 Issue 3 - 2018

\author{
Manoj Gundalia \\ Department of Civil Engineering, Dr. Subhash Technical Campus, \\ India
}

\begin{abstract}
Correspondence: Manoj Gundalia, Department of Civil Engineering, Dr. Subhash Technical Campus, India, Email mjgundalia@gmail.com
\end{abstract}

Received: December 05, 2017 | Published: May 04, 2018

\section{Introduction}

Infiltration is the intake of water into the soil profile and it is one of the major components of the hydrologic cycle. According to ${ }^{1}$ Infiltration is the methodology by which water moves descending at the soil surface pass in the soil. Itseparates water into two major hydrologic components - surface runoff and subsurface recharge and it is usually measured by the depth of the water layer that can enter the soil in unit time.Infiltration is a complex process with many factors contributing to the infiltration rate. Water that falls as precipitation may run over land eventually reaching streams, lakes, rivers and oceans or infiltrate through the soil surface, into the soil profile. Water that runs off over land causes erosion, flooding and degradation of water quality. Infiltration, on the other hand, constitutes the sole source of water to sustain the growth of vegetation, is filtered by the soil which removes many contaminants through physical, chemical and biological processes, and replenishes the ground water supply to wells, springs and streams. ${ }^{2,3}$ Infiltration is critical because it supports life on land on our planet. The ability to quantify infiltration is of great importance in many hydrological problems such as runoff estimation, watershed management, soil moisture budgeting, irrigation planning, prediction of flooding, erosion and pollutant transport.

Infiltration rate characterizes by time from onset of rain or irrigation, initial water content of the soil, hydraulic conductivity, surface conditions, and profile depth and layering. ${ }^{4}$ Several wellknown empirical models such as Kostiakov, Horton, and Holtan, and approximate physically based models like those of Green and Ampt and Philip equations are used to estimate infiltration rate for field applications. Unfortunately, single model does not provide consistently better predictions for infiltration in different types of soil. Therefore, it is difficult for researchers to select the most suitable model to estimate infiltration rate. In the present study, a complementary error function peak (ERFC) based model is proposed to determine infiltration rate for the Ozat Watershed of Gujarat (India).The constant infiltration ratesof different soils of the study area were calculated by double ring infiltrometer method, and compared with calculated values from Horton's, Modified Kostiakov, and Green-Ampt infiltration models along with proposed model. Infiltration is the process by which water enters the soil. It separates water into two major hydrologic components - surface runoff and subsurface recharge. The assessment of runoff risk has assumed an increased importance because of concerns about the associated pollution hazards. Accurate determination of infiltration rates is essential for reliable prediction of surface runoff. As environmental impact assessments are concerned with long-term effects, it is essential that the infiltration data on which they are based should be reasonably stable over decades. For planning purposes it is essential to know the stability of infiltration data for the infiltration capacity of individual soils is adequate to cope with the anticipated hydrologic loads. A high infiltration rate is generally desirable for plant growth and the environment. In some cases, soils that have unrestricted water movement through their profile can contribute to environmental concerns if misapplied nutrients and chemicals reach groundwater and surface water resources via subsurface flow. In India also, very few studies have been reported that focused on infiltration based rainfall simulator experiment. ${ }^{5}$

A few studies had been carried out ${ }^{6-9}$ for estimating the infiltration rates in various basins in different parts of India using double ring infiltrometer. The appearance of layered soil is more common than uniform soil in nature with the latter being the exception, vertical infiltration in layered soils has drawn much attention and been studied by many authors. The constant rate approached after a sufficiently large time is referred to as the steady-infiltration rate. The process is described by the equations of ${ }^{10,11}$ which show a decreasing infiltration rate as a function of time. Many researchers have evaluated the models 
by comparing the computed and observed infiltration rates. ${ }^{12-15}$ Most recent reports ${ }^{16-21}$ have shown that the ability to quantify infiltration is of great importance in soil management, especially, in irrigation and drainage designs. Hence, a robust infiltration model, that can correctly predict the actual infiltration, can be quite effective in planning and designing of water resources systems. ${ }^{19}$ The main objective of this study was to develop a model for determination of infiltration rate with specific focus on:

1. Deriving the parameter values of Horton's, modified Kostiakov and Green Ampt models for the different soils of Ozat watershed

2. Determine the prediction accuracy ofmodels using standard statistical criteria refined Willmott's index $\left(d_{r}\right)$ (Dimensionless statistic) and mean absolute error (MAE) (error index statistic) and

3. Make recommendation for the best model to use for the study area.

\section{Study area and data collection}

Ozat is a river flowing in western India in Gujarat state whose origin is near Visavadar and meets in Arebian Sea. Ozat is third largest river of Saurashtra region after Bhadar and Shetrunji rivers. Ozat watershed considered in this study geographically located within the latitudes $21^{\circ}$ $19^{\prime} \mathrm{N}$ to $21^{\circ} 33^{\prime} \mathrm{N}$ and the longitudes $70^{\circ} 37^{\prime} \mathrm{E}$ to $70^{\circ} 59^{\prime} \mathrm{E}$ respectively. Satellite Imageries: The Indian Remote Sensing satellite with Linear Imaging Self Scanning sensors (IRS-LISS III) satellite data of scale 1:50000 were collected from Bhaskaracharya Institute for Space Applications and Geo- Informatics (BISAG), Gandhinagar and used to prepare soil map of the study area. Soil taxonomy developed by United States Department of Agriculture and the National Cooperative Soil Survey is widely used system for classifying soils. The prime objective of soil taxonomy is to develop a hierarchical classification that reflects the relationships between different soils, and between soils and the factors responsible for their character. According to ${ }^{22}$ many

Table I Spatial variation of soil properties in the Ozatwatershed

\begin{tabular}{lll}
\hline Area & Land without soil & Entisols \\
$\mathrm{Km}^{2}$ & 38.9145 & 7.4891 \\
$\%$ & 11.08 & 2.13 \\
\hline
\end{tabular}

\section{Infiltration models}

The following infiltration models were assessed for finding best fitting model to observed field infiltration rate data.

\section{Horton's model}

The Horton model of infiltration ${ }^{11,24}$ is one of the best-known models in hydrology. Horton recognized that infiltration capacity (f) decreased with time until it approached a minimum constant rate $\left(f_{c}\right)$. He derived his equation for infiltration, which describes a pattern of exponential decay of infiltration rate from this basic relationship. The final form of the Horton equation is expressed as

$$
\mathrm{f}=\mathrm{f}_{\mathrm{c}}+\left(\mathrm{f}_{\mathrm{o}}-\mathrm{f}_{\mathrm{c}}\right) \mathrm{e}^{-k_{h} \mathrm{t}}(1)
$$

Where

$\mathrm{f}$ is infiltration capacity at any time t.

$\mathrm{f}_{\mathrm{c}}$ is final steady state infiltration capacity. countries have developed soil classificationsystems for national use, but Soil Taxonomy ${ }^{23}$ is used worldwide. There are 12 recognized soil orders in the world. The three soil orders, Entisols, Inceptisols, and Vertisols, are mapped in the study region.Locations for measurement of infiltration rate were selected based on different types of soil in the study area (Figure 1). The classification of the soils of Ozat watershed based on soil taxonomy is presented in Table 1.The total geographical area of the Ozat watershed is $351.0633 \mathrm{Km}^{2}$ andthe major crops grown are Ground nut, wheat and Cotton. Periodic insufficient rainfall pattern, limited water storage capacity of aquifer and natural water conservation are vital issues for this region. Water availability is a critical factor in this area. Infiltration is the important parameter and significantly assessment of soil moisture, determination of surface runoff, to determination of efficiency of water harvesting structure in ground water recharging, and therefore accurate estimation of infiltration is needed.

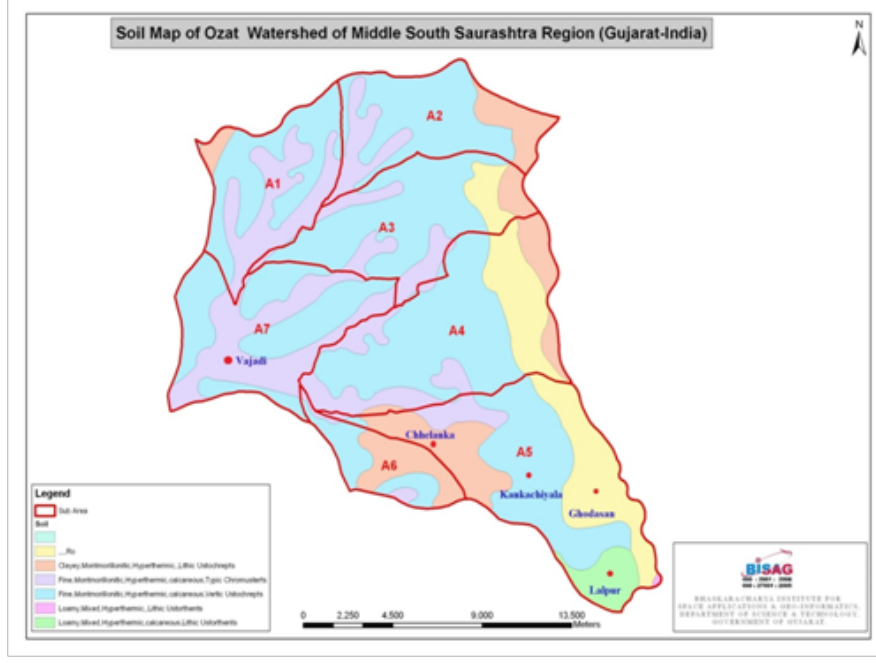

Figure I Soil map with selected location for measurement of infiltration rate.

$\begin{array}{lll}\text { Inceptisols } & \text { Vertisols } & \text { Total } \\ 229.9799 & 74.6798 & 351.0633 \\ 65.51 & 21.27 & 100.00\end{array}$

$\mathrm{f}_{\mathrm{o}}$ is initial infiltration capacity

$\mathrm{k}_{\mathrm{h}}$ Horton's constant representing rate of decrease in infiltrationcapacity

$\mathrm{t}$ is time in hours.

$\mathrm{He}$ attributed this decrease in infiltration primarily to factors operating at the soil surface rather than to flow processes within the soil. ${ }^{25}$ Horton's equation has been widely used because it generally provides a good fit to data. Although the Horton equation is empirical in that $k_{h}, f_{c}$ and $f_{o}$ must be calculated from experimental data, rather than measured in the laboratory, it does reflect the laws and basic equations of soil physics. ${ }^{26}$ However, the Horton equation is cumbersome in practice since it contains three constants that must be evaluated experimentally. ${ }^{4} \mathrm{~A}$ further limitation is that it is applicable only when rainfall intensity exceeds fc. ${ }^{2,27}$ criticized on its assumptions that hydraulic conductivity is independent of the soil water content. Horton's approach has also been criticized because he neglects the role of capillary potential gradients in the decline of 
infiltration capacity over time and attributes control almost entirely on surface conditions. He also discovered that Horton's perceptual model was far more sophisticated and complete than normally presented in hydrological texts.

\section{Modified kostiakov model}

Kostiakov $^{10}$ and independently ${ }^{28}$ proposed a simple empirical infiltration equation based on curve fitting from field data. The major limitation of the Kostiakov-Lewis variant, also known as the "Modified Kostiakov" is its reliance on the zero final intake rates. In most cases the infiltration rate instead approaches a finite steady value, which in some cases may occur after short periods of time. ${ }^{29}$ proposed a modification to Kostiakov's equation by adding a constant to the equation that represents the final infiltration rate reached when the soil becomes saturated after prolonged infiltration.

$$
\mathrm{f}=\mathrm{k}_{\mathrm{k}} \mathrm{at}^{(\mathrm{a}-1)}+\mathrm{f}_{\mathrm{c}}
$$

\section{Where}

$\mathrm{k}_{\mathrm{k}}$ and a are constants whose values depends on soil type..$^{30}$ showed that the ' $\mathrm{k}$ ' and ' $\mathrm{a}$ ' terms of the equation do have physical meaning even though several authors have described it as purely empirical. ${ }^{31}$ however, found empirically that the value of 'a' was consistently less than one, he recommended the modified Kostiakov equation for routine modeling of the infiltration process on soils with rapid water intake rates.

\section{Green-amptmodel}

Green, $\mathrm{Ampt}^{32}$ proposed an approximate model that directly applies Darcy's law. The original equation was derived for infiltration from a ponded surface into a deep homogeneous soil with uniform initial water content. The Green and Ampt (GA) model has been found to apply best to infiltration into uniform, initially dry, coarse textured soils which exhibit a sharply defined wetting front. ${ }^{33}$ GA applies the physical principles governing infiltration for simplified boundary and initial conditions. It imply ponded surface conditions from time zero on, ${ }^{4}$ and is based on assumptions of uniform movement of water from the surface down through deep homogenous soil with a well-defined wetting front. These assumptions are more valid for sandy soils than for clay soils and reduce the amount of physical soil data needed from that of numerical solutions, but also limit their applicability under changing initial and boundary conditions ${ }^{34}$ This pattern is often called a piston displacement profile or plug flow.

$$
\mathrm{f}=\mathrm{b}+\frac{\mathrm{c}}{\mathrm{F}}
$$

\section{Where}

$\mathrm{F}$ is cumulative infiltration.

$\mathrm{b}$ and $\mathrm{c}$ are Green-Ampt parameters of infiltration.

The GA equation produced reasonably good predictions for nonuniform soil profiles that become denser with depth, ${ }^{35}$ for profiles where hydraulic conductivity decreases with depth ${ }^{36}$ or increases with depth, ${ }^{37}$ and for soils with partially sealed surfaces. ${ }^{33,36}$ described a tabular procedure for calculating the GA relationship between cumulative infiltration and time for soils with non-uniform initial water contents and hydraulic conductivities. GA model parameters can be estimated from soil water properties and do not require measured infiltration data. Thus it should be able to produce estimates at lower cost than empirical equations.

\section{Model development}

In spite of the wider variety of models no generally accepted method to estimate infiltration rate is applicable to all field conditions or problems. On the other hand, accuracy and reliability of these methods vary widely according to regional soil types..$^{38}$ stated that the various models can estimate different values of the final soil infiltration rate which seems incorrect as the parameter is soil-dependent. Therefore, it is difficult for many scientists to select the most suitable equation to use for a given study. The empirical equations, such as Kostiakov and Horton equations provide infiltration rates based on measured field data and therefore provide more realistic estimates with calibrated parameters for the same site or site having similar conditions. The model formulation was considered as infiltration rate has a tendency to decrease with the increase of time. The complementary error function is important special function which appears in the solutions of diffusion problems in heat, mass and momentum transfer, probability theory, the theory of errors and various branches of mathematical physics. The error function (erf) is obtained by integrating the normalized Gaussian distribution. The complementary error function (erfc) equals one minus the error function and is defined as:

$$
\operatorname{erfc} \mathrm{x}=1-\frac{2}{\sqrt{\delta}} \int_{\mathrm{x}}^{\infty} \mathrm{e}^{-\mathrm{t}^{2}}
$$

$$
t=\frac{x}{\sqrt{2 \sigma}}
$$

In the present work, an alternative strategy was followed; the f-t relationship is expressed in terms of the complementary error function erfc with argument $(\beta * t)$ as:

$$
\mathrm{f}=\alpha^{*} \operatorname{ERFC}\left(\beta^{*} \mathrm{t}\right)+\mathrm{f}_{\mathrm{c}}
$$

Where

$\alpha$ and $\beta$ are constants

\section{Results and discussion}

Double ring infiltrometer method was used formeasurement of infiltration rates at selected sites. $30 \mathrm{~cm}$ diameter inner ring and $60 \mathrm{~cm}$ diameter outer ring with $25 \mathrm{~cm}$ deep were driven at about $15 \mathrm{~cm}$ deep in soil by using falling weight type hammer strikingon a wooden plank placed on top of ring uniformlywithout or undue disturbance to soil surface. Measurements were taken at regular time interval of $5,10,15,20,25 \mathrm{~min}$. up to getting a constant infiltration rate. The measured steady state infiltration rate and other important properties of the soil at selected sites are shown in Table 2. According to soil taxonomy, the Ozat watershed is characterized by mainly three types of soil, i.e., Entisols, Inceptisols and Vertisols (Table1). Entisols are immature soils with little evidence of soil formation and indicated by "ent". By texture, they are sandy-clay, loam or clay-loam to clay. Structurally these soils are weak, mainly subangular, blocky and sometimes crumb-like, calcareous and alkaline in nature. Inceptisols are designated by "ept". They are young soils with weakly developedsubsurface horizons but more developed than Entisols. These soils are texturally silty-loam to clay and neutral to alkaline in reaction. Vertisols are fairly deep, heavy clay soils, and have no definite structure. Because of the montmonllonitic nature of the clay minerals they shrink and crack when dry and expandwhen moist. The soils are saline and texturally sandy loam with silty clay loam. Vertisol are indicated by "ert" and characterized by low noncapillary pore spacewhich prevents drainage of excess water. The 
parameters of selected models were optimized by using solver tools of Microsoft excel to improve their performance. Optimized values of the parameters of different models for the selected sites of the study areaare presented in Table 3. It is evident from the Table 3 that the values of parameters of infiltration models vary for different soil types. The values of the parameters estimated were then incorporated into the respective models and the capability of each model to simulate infiltration rate for site was evaluated by comparing the models simulated data with field measured data.

Models evaluation was carried out with two popular statistical criteria refined Willmott's index $\left(d_{r}\right)$ (Dimensionless statistic) and mean absolute error (MAE) (error index statistic). MAE is the most natural and unambiguous measure of average error magnitude. It provides more robust measure of average model error, since it is not influenced by extreme outliers and estimates model error in the units of the variable. ${ }^{39}$ A higher MAE value indicates poor model performance and vice versa. MAE $=0$ indicates a perfect fit. The $d_{r}$ is applied to quantify the degree to which values of measured infiltration rate are captured by the selected models. The range of $d_{r}$ is from -1.0 to 1.0. $\mathrm{A} \mathrm{d}_{\mathrm{r}}$ of 1.0 indicates perfect agreement between model and observation and $\mathrm{a} \mathrm{d}_{\mathrm{r}}$ of -1.0 indicates either lack of agreement between the model and observation or insufficient variation in observations to adequately test the model. The results of the statistical analysis of all the models versus observed measure values for selected sites are presented in Tables 4 respectively. From analysis it was found that for all soil type proposed model was best fitting with lower MAE and higher $d_{r}$ values. The proposed model with a MAE of $0.27 \mathrm{~cm} /$ $\mathrm{hr}$ and $\mathrm{d}_{\mathrm{r}}$ value 0.90 most closely predicted the measured infiltration rate for Chhelanka, followed by Horton's model for Chhelanka and Vajadi with MAE values of $0.35 \mathrm{~cm} / \mathrm{hr}$ and $0.90 \mathrm{~cm} / \mathrm{hr}$ and $\mathrm{d}$ values of 0.88 and 0.75 respectively. Kostiakov Model provided good results with MAE of $0.68 \mathrm{~cm} / \mathrm{hr}$ and $\mathrm{d}_{\mathrm{r}}$ value 0.71 for Lalpur site. Green-Ampt Model provided less accurate estimates for all sites.Performances of all modelsfor selected sites are shown in Figures 2-5.

Table 2 Various soil properties and final rate of infiltration at selected sites

\begin{tabular}{|c|c|c|c|c|c|c|}
\hline Selected Sites & Soil type & $\begin{array}{l}\text { Date of } \\
\text { exp. }\end{array}$ & $\begin{array}{l}\text { Temp. } \\
\left({ }^{\circ} \mathrm{C}\right)\end{array}$ & $\begin{array}{l}\text { Dry density } \\
\left(\mathrm{Kg} / \mathbf{m}^{3}\right)\end{array}$ & $\begin{array}{l}\text { Moist. } \\
\text { cont. (\%) }\end{array}$ & $\begin{array}{l}\text { Steady state infilt. } \\
\text { rate }(\mathrm{cm} / \mathrm{hr})\end{array}$ \\
\hline Lalpur & $\begin{array}{l}\text { Loamy, mixed, hyperthermic, calcareous, } \\
\text { lithicustorthents }\end{array}$ & $\begin{array}{l}20^{\text {th }} \text { Feb., } \\
2017\end{array}$ & 26 & 1109 & 15 & 2.39 \\
\hline Kankachiyala & $\begin{array}{l}\text { Fine, montmorrilonitic, hyperthermic, } \\
\text { calcareous, verticustochrepts }\end{array}$ & $\begin{array}{l}1^{\text {st }} \text { Feb., } \\
2017\end{array}$ & 22 & 1606 & 3.45 & 3.6 \\
\hline Chhelanka & $\begin{array}{l}\text { Clayey, montmorrilonitic, hyperthermic, lithic, } \\
\text { ustochrepts }\end{array}$ & $\begin{array}{l}25^{\text {th }} \text { Mar., } \\
2017\end{array}$ & 26 & 1572 & 17.39 & 4.32 \\
\hline Vajadi & $\begin{array}{l}\text { Fine, montmorrilonitic, hyperthermic, } \\
\text { calcareous, typicchromusterts }\end{array}$ & $\begin{array}{l}12^{\text {th }} \text { Jan., } \\
2017\end{array}$ & 18 & 1089 & 14 & 8.16 \\
\hline
\end{tabular}

Table 3 The values of optimized parameters of infiltration models for selected sites

\begin{tabular}{|c|c|c|c|c|c|c|c|}
\hline \multirow[t]{2}{*}{ Selected sites/ Soil orders } & \multirow{2}{*}{$\begin{array}{l}\text { Horton's model } \\
K_{h}\end{array}$} & \multicolumn{2}{|c|}{ Modified kostiakov model } & \multicolumn{2}{|c|}{ Green - ampt model } & \multicolumn{2}{|c|}{ Proposed model } \\
\hline & & $\mathbf{K}_{\mathrm{k}}$ & $\mathbf{a}$ & $\mathbf{b}$ & c & $\alpha$ & $\beta$ \\
\hline Lalpur (Entisols) & 2 & 1748.15 & 0.57 & 2.44 & 3.74 & 6.23 & 1.49 \\
\hline Kankachiyala (Inceptisols) & 1.26 & 1921.06 & 0.69 & 4.28 & 12.51 & 6.7 & 0.44 \\
\hline Chhelanka (Inceptisols) & 1.27 & 1552.28 & 0.73 & 4.71 & 8.59 & 5.97 & 0.58 \\
\hline Vajadi (Vertisols) & 6.22 & 3245.36 & 0.66 & 5.76 & 34.49 & 64.04 & 8.41 \\
\hline
\end{tabular}

Table 4 Performance of selected models and proposed model for selected sites

\begin{tabular}{|c|c|c|c|c|c|c|c|c|}
\hline \multirow{2}{*}{ Selected sites/ Soil types } & \multicolumn{2}{|c|}{ Horton's model } & \multicolumn{2}{|c|}{ Modified kostiakov model } & \multicolumn{2}{|c|}{ Green - ampt model } & \multicolumn{2}{|c|}{ Proposed model } \\
\hline & MAE (cm/hr) & dr & MAE (cm/hr) & dr & MAE (cm/hr) & dr & MAE (cm/hr) & dr \\
\hline Lalpur (Entisols) & 0.69 & 0.63 & 0.68 & 0.71 & 1 & 0.47 & 0.32 & 0.89 \\
\hline Kankachiyala (Inceptisols) & 0.69 & 0.83 & 0.48 & 0.82 & 0.74 & 0.65 & 0.42 & 0.87 \\
\hline Chhelanka (Inceptisols) & 0.35 & 0.88 & 0.45 & 0.81 & 0.86 & 0.51 & 0.27 & 0.9 \\
\hline Vajadi (Vertisols) & 0.9 & 0.75 & 1.6 & 0.66 & 1.37 & 0.67 & 0.58 & 0.86 \\
\hline
\end{tabular}




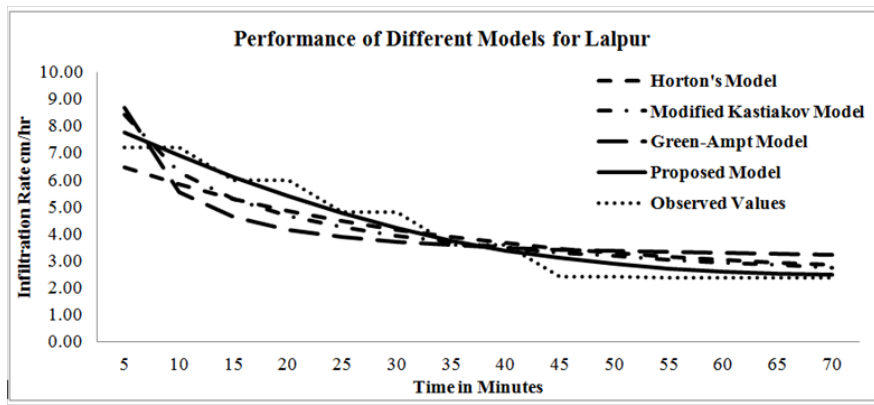

Figure 2 Performance of different models for Lalpur (Entisols).

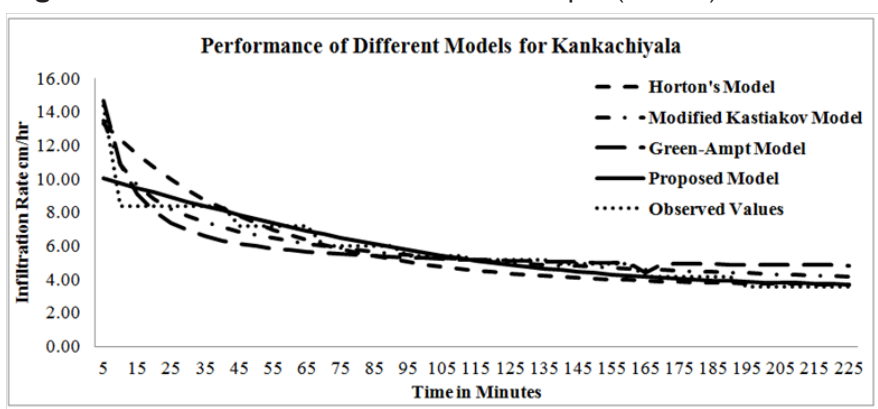

Figure 3 Performance of different models for Kankachiyala (Inceptisols).

\section{Conclusion}

This paper investigates the ability of the novel infiltration model based on based on Complementary Error Function Peak in estimating the infiltration rate from actual field data in comparison to other three popular models in like situations. From the research work the following conclusions are drawn:

a. Steady state of infiltration rate of Lalpur, Kankachiyala, Chhelanka, and Vajadisites $2.39 \mathrm{~cm} / \mathrm{hr}, 3.6 \mathrm{~cm} / \mathrm{hr}, 4.32 \mathrm{~cm} / \mathrm{hr}$ and $8.16 \mathrm{~cm} / \mathrm{hr}$ respectively.

b. The parameters of infiltration models vary for different soil types. Which is clearly shows thatInfiltration rate gets affected by soil types.

c. Horton's model can be effectively used for predicting infiltration rate in Inceptisols and Vertisols.

d. Modified Kostiakov model can be used to predict infiltration rate accurately in Entisols.

e. From analysis it was found that for all type of soil proposed model was best fitting with lowest MAE and $d_{r}$ highest values.

\section{Acknowledgements}

None.

\section{Conflict of interest}

The author declares there is no conflict of interest.

\section{References}

1. Gregory JH, Dukes MD, Miller GL, et al. Analysis of double-ring infiltration techniques and development of a simple automatic water delivery system. Plant Management Network. 2005;1-7.

2. Rawls WJ, Ahuja LR, Brakensiek DL, et al. Infiltration and soil water movement. McGraw- Hill, Inc: Handbook of Hydrology. 1993.

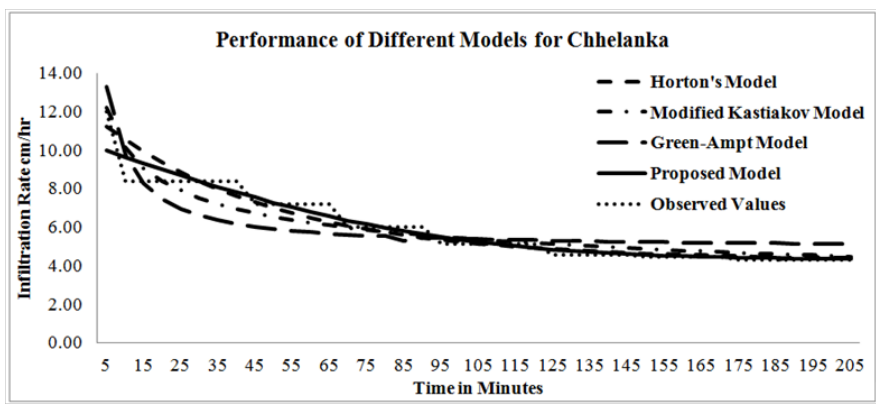

Figure 4 Performance of different models for chhelanka (Inceptisols).

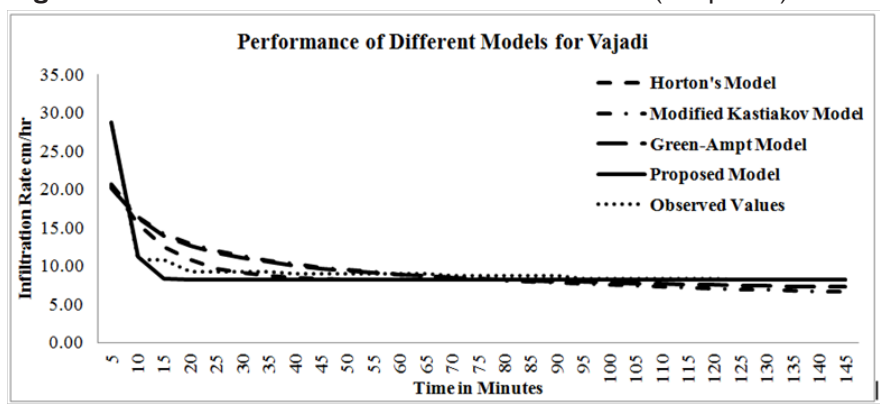

Figure 5 Performance of different models for Vajadi (Vertisols).

3. Oram B. Hydrological Cycle. Watershed Assessment, Education, Training, Monitoring Resources in Northeastern Pennsylvania. Wilkes University. Environmental Engineering and Earth Sciences Department. Wilkes-Barre, PA. 2005

4. Hillel D. Environmental Soil Physics. Academic Press. San Diego, CA. 1998.

5. Bhardwaj, Singh R. Development of a portable rainfall simulator infiltrometer for infiltration, runoff and erosion studies. Agricultural Water Management. 1992;22(3):235-248.

6. Rawat JS, Purandara PK, Chandrakumar S. Infiltration studies in the Malaprapa and Ghataprapa catchment. NIH, Roorkee report. 1993.

7. Soni P, Singh SR. Average infiltration from cylinder infiltrometer test. Indian Soc of Agri Engineers. 1988.

8. Soni P, Naithani S, Matur HN. Infiltration studies under different vegetation cover. Indian J of Forestery. 1985;8(3):170-173.

9. Srinivasan K, Poongothai S. Assessment of Infiltration rate of a Tank Irrigation Watershed of Wellington reservoir, Tamilnadu, India. American Journal of Engineering Research. 2013;2(7):41-48.

10. Kostiakov AN. On the dynamics of the coefficient of water percolation in soils and on the necessity of studying it from a dynamic point of view for the purposes of amelioration. Moscow, Russia: Transactions $6^{\text {th }}$ Congress of International Society of Soil Science. 1932;17-21.

11. Horton RE. An approach toward a physical interpretation of infiltrationcapacity. Soil Sci Soc Am Proc. 1940;5:399-417.

12. Hopmans J. Evaluation of various infiltration models. Sci Agric. 1995;140:5-8

13. Mishra SK, Tyagi JV, Singh VP. Comparison of infiltration models. Hydrol. Processes. 2003;17(13):2629-2652.

14. Chahinian N, Moussa R, Andrieux P, et al. Comparison of infiltration models to simulate flood events at the field scale. J Hydrol. 2005;306(14):191-214. 
15. Haghighi F, Gorji M, Shorafa M, et al. Evaluation of some infiltration models and hydraulic parameters. Span J Agric Res. 2010;8(1):210 217.

16. Mirzaee S, Zolfaghari AA, Gorji M, et al. Evaluation of infiltration models with different numbers of fitting parameters in different soil texture classes. Arch Agron Soil Sci. 2013;60(5):681-693.

17. Stewart RD, Rupp DE, Abou Najm MR, et al. Modelling effect of initial soil moisture on sorptivity and infiltration. Water Resources Research. 2013;49(10):7037-7047.

18. Khalid AA, Tuffour HO, Bonsu M. Influence of Poultry Manure and NPK Fertilizer on Hydraulic Properties of a Sandy Soil in Ghana. International Journal of Scientific Research in Agricultural Sciences. 2014;1(2):16-22.

19. Parhi PK. Another look at Kostiakov, modified Kostiakov and revised modified Kostiakov infiltration models in water resources applications. International Journal of Agricultural Sciences. 2014;4(3):138-142.

20. Tuffour HO, Bonsu M, Khalid AA. Assessment of soil degradation due to compaction resulting from cattle grazing using infiltration parameters. International Journal of Scientific Research in Environmental Sciences. 2014a;2(4):139-149.

21. Tuffour HO, Bonsu M, Khalid AA, et al. Scaling approaches to evaluating spatial variability of saturated hydraulic conductivity and cumulative infiltration of an Acrisol. International Journal of Scientific Research in Knowledge. 2014b;2(5):224-232.

22. Krasilnikov PJ, Ibanez Marti, Arnold R, et al. A handbook of soil terminology, correlation and classification. $1^{\text {st }}$ edition. Earthscan, Sterling, VA. 2009

23. Soil Survey Staff. Soil taxonomy: A basic system of classification for making and interpreting soil surveys. United States Government Printing Office, Washington, USA: USDA-NRCS Handbook 436. 1999

24. Horton RE. Analysis of runoff plot experiments with varying infiltration capacity. Transactions of the American Geophysicists. 1939;20(4):693694.

25. Xu CY. Approximate infiltration models. Uppsala University Department of Earth, Air and Water Sciences. Uppsala, Sweden. Hydrologic Models. 2003.
26. Chow VT, Maidment DR, Mays LW. Applied Hydrology. New York, NY: McGraw-Hill. 1988.

27. Novotny V, Olem H. Water Quality; Prevention, Identification, and Management of Diffuse Pollution. New York, NY: Van Nostrand Reinhold. 1994.

28. Lewis MR, MILNE WE. Analysis of border irrigation. Agric Eng. $1938 ; 19(6): 267-272$

29. Mezencev VJ. Theory of formation of the surface runoff. Meteorologiae Hidrologia. 1948;3:33-40.

30. Fok YS. Derivation of Lewis-Kostiakov intake equation. Journal of Irrigation and Drainage Engineering. 1986;112:164-171.

31. Mbagwu JSC. Testing the goodness of fit of infiltration models for highly permeable soils under different tropical soil management systems. Soil \& Tillage Research. 1995;34(3):199-205.

32. Green WH, Ampt GA. Studies on soil physics: I. Flow of air and water through soils. J Agric Sci. 1911;4(1):1-24

33. Hillel D, Gardner WR. Transient infiltration into crust topped profiles. Soil Science. 1970;109:69-76.

34. Haverkamp R, Rendon L, Vachaud G. Infiltration equations and their applicability for predictive use. In: Yu- SI Fok, editor. Infiltration Development and Application. Honolulu, Hawaii. 1987;142-152.

35. Childs EC, Bybordi M. The vertical movement of water in stratified porous material. 1. Infiltration. Water Resources Research. $1969 ; 5(2): 446-459$

36. Bouwer H. Infiltration of water into nonuniform soil. Journal of Irrigation and Drainage Division, ASCE. 1969;95(4):451-462.

37. Bouwer H. Infiltration into increasingly permeable soils. Journal of Irrigation and Drainage Division.1976;102(1):127-136.

38. Singh VP. Elementary hydrology. Prentice Hall: Englewood Cliffs, NJ, USA. 1992.

39. Legates DR, McCabe GJ. Evaluating the Use of "Goodness-of-Fit" Measures in Hydrologic and Hydroclimatic Model Validation. Water Resources Research. 1999;35:233-241. 